Proc $2^{\text {nd }}$ APCRS

\title{
Spatial variability in reef habitat structure in southern central Philippines
}

\author{
Karen A. VILLARTA ${ }^{1, *}$, Wilfredo L. CAMPOS ${ }^{1}$ and Pacifico D. BELDIA II ${ }^{2}$ \\ ${ }^{1}$ OceanBio Laboratory, Division of Biological Sciences, College of Arts and Sciences, University of the Philippines \\ Visayas, 5023 Miag-ao, Iloilo, Philippines \\ ${ }^{2}$ Conservation International Philippines, 6 Maalahanin St., Teachers Village, Diliman, Quezon City, 1101 Philippines \\ * Corresponding author: Karen A. VILLARTA \\ E-mail: karenvillarta@yahoo.com and oceanbio2002@yahoo.com
}

\begin{abstract}
This study was conducted to provide information necessary for deriving indicators in reef MPA sites by means of characterizing spatial trends in benthic community structures in an attempt to provide traces requisite in understanding coral reef dynamics and ultimately, determining supplemental site-specific management approaches. This is part of a 7-year program aimed at conserving biological diversity in four focal areas in the Philippines situated at different geographic locations in the country. A total of 126 transects were surveyed in two focal areas, 60 in Surigao del Sur and 66 in Danajon Bank, Bohol, surveyed in June and August 2008, respectively. For both areas, live hard coral cover showed variability among transects within MPA sites (200-400 m apart) as well as between MPA sites (10-60 km apart), although MPA sites located within only a few kilometers from each other tend to be similar in terms of live hard coral coverage. However, a significant degree in variation was observed between MPAs in Surigao del Sur, which have exposed reef systems, compared with those observed in Danajon Bank, Bohol, which are all within a double barrier reef system. In Surigao del Sur, variability in LHC cover between inshore MPAs and island MPAs was also found to be significantly different. Results of spatial correlation between live hard coral and total algal cover between the two focal areas is discussed further.
\end{abstract}

Keywords Spatial variability, MPA, Surigao del Sur, Danajon Bank

\section{Introduction}

Assessments of coral reef communities in marine protected areas (MPA) in the Philippines are important in monitoring reef health condition towards conservation of biodiversity (see Philreefs, 2003). However, the assessments are mostly localized and conducted over diminutive spatial and temporal scales. Most of the data available include percent covers of benthic lifeforms as well as fish composition, abundance and biomass from surveys conducted within MPA sites. MPAs located nearby each other are also frequently treated separately thus spatial continuity is not established. Changes in the distribution and abundance of corals must be reflected in changes in their spatial patterns (Bradbury and Young, 1983).

This study is part of a 7-year program aimed at conserving biological diversity in four focal areas in the Philippines situated at different geographic locations in the country, namely, Calamianes in Palawan, Surigao del Sur, Tawi-Tawi and Danajon Bank in Bohol. The aim of this study is to characterize and compare the spatial variability in benthic life form characteristics (live hard coral 


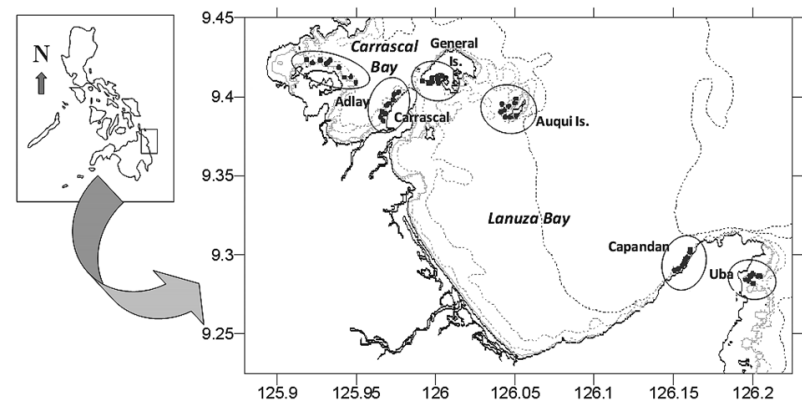

Fig. 1 Map showing the location of dive stations (gray dots) in the six MPA sites (gray ellipses) surveyed in MayJune 2008 in Carrascal \& Lanuza Bays, Surigao del Sur, in South Philippine Sea. Note: Names in bold black letters refer to names of the MPAs.

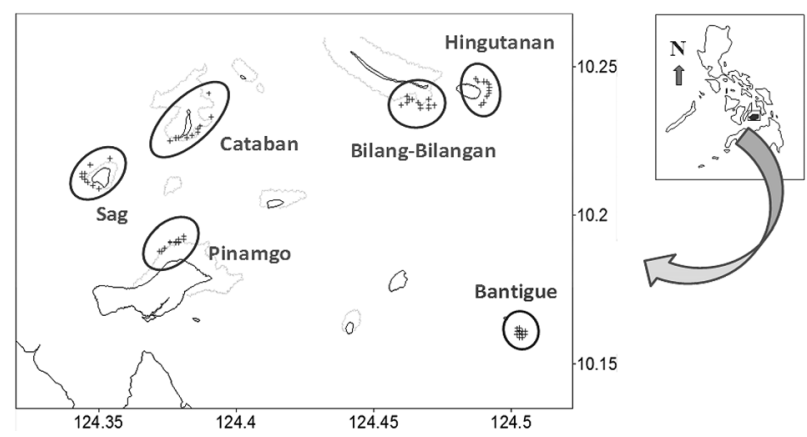

Fig. 2 Map showing the location of dive stations (gray crosses) in the six MPA sites (gray ellipses) surveyed in August 2008 in Danajon Bank, Bohol, central Philippines. Note: Names in bold black letters refer to names of the MPAs.

and algal cover) estimated from replicated transects (stations) in MPA sites from two of the four focal areas namely, Surigao del Sur and in Danajon Bank, Bohol. The sites in Surigao del Sur are located along the mainland coast (inshore) and on islands towards the east which are exposed to the open South Philippine Sea (Pacific Ocean) (Fig. 1). In Bohol, on the other hand, all six sites are located within a double barrier reef system separating the main island (inshore) from the open deeper Camotes Sea (Danajon Bank) (Fig. 2).

\section{Material and methods}

\section{Study Areas}

The surveys were conducted from 31 May to 4 June 2008 in Carrascal and Lanuza Bays in the province of Surigao del Sur, Philippines. The study area is located at the eastern coast of the island of Mindanao, southern Philippines, and faces the Philippine Sea. A total of 60 dive transect stations were surveyed during this period, ten in each of six MPA sites. Figure 1 shows the station locations in the following MPA sites: Auqui Is., Adlay, Carrascal, General Is., Capandan and Uba.

In Danajon Bank, Bohol, surveys were conducted on 11-16 August, 2008. The study area is located northeast in the island of Bohol in central Philippines. A total of 66 dive transect stations were surveyed during this period, ten in the three MPA sites (Cataban, Pinamgo and Sag) and 12 in the other three sites (Bilang-Bilangan, Hingutanan and Bantigue). The station locations in the $6 \mathrm{MPA}$ sites surveyed in Danajon Bank, Bohol are shown in Figure 2.

\section{Reef Substrate Characterization}

Benthic lifeform cover was determined using the LIT or line intercept technique (English et al. 1994). At each dive station, one $50 \mathrm{~m}$ transect line was set parallel to the shore along the reef slope wherein all life forms intercepted by the transect line are recorded. Depth of transect varied among stations depending on the extent of the reef and depth of the reef slope. Benthic cover was determined by noting the length of the transect interval under the fiberglass tape measure for each coral lifeform, other taxonomic groups, as well as substrate type. The data were then summarized in the following categories: Live hard coral (LHC), live soft coral (LSC), dead coral and coral rubble (DC), dead coral with algae (DCA), algae on substrate other than dead coral/rubble (Other Algae), other fauna (Other Biota), and rock/ mud/ sand/ water (Abiotic). Measurements of other physical features in each station are discussed in Campos (2008).

\section{Data Analysis}

Univariate analysis was employed to examine varia- 
bility in live hard coral (LHC) and total algae (DCA+ Other Algae) within MPAs and between MPA sites.

Variogram analysis was used to investigate the effect of distance on the variation in LHC between survey sites using the Surfer 8 software. Variograms characterize the spatial continuity or roughness in a data set (Barnes, 1991) and was calculated according to:

$$
\gamma(\mathrm{h})=\frac{1}{2 \mathrm{~N}(\mathrm{~h})} \sum_{\mathrm{i}=1}^{\mathrm{N}(\mathrm{h})}\left[\mathrm{Z}\left(\mathrm{X}_{\mathrm{i}}+\mathrm{h}\right)-\mathrm{Z}\left(\mathrm{X}_{\mathrm{i}}\right)\right]^{2}
$$

where $\gamma$ is a measure of between-site variability, $h$ is the distance (lag) between two locations, $\mathrm{N}(\mathrm{h})$ is the number of pairs of positions (data points) $(x i$; $x i+h)$, $x i$ is the position of the survey sites and $\mathrm{Z}(\mathrm{xi})$ is the value of LHC at location xi (Armstrong et al. 1992).

All percentage data were expressed as proportions and arcsin-transformed (Zar, 1996), to stabilize variance, before analyses were performed.

\section{Results and Discussion}

\section{Surigao del Sur}

Live hard coral cover ranged from 21 to $87 \%$ across all stations in Surigao del Sur (Table 1) with high LHC cover in Auqui and General Is (Fig. 3). Uba MPA showed the lowest LHC cover (mean $=37.2 \%$ ) and was dominated mostly by DCA, other algae and other biota (Table 1). Differences are shown between inshore MPAs, which have relatively low LHC cover and high DCA and algal cover (Fig. 4), and the three island MPAs, which exhibited a much higher LHC cover (Fig. 3). The low LHC in in- shore MPAs may be an effect of greater exposure to anthropogenic activities, i.e pollution and siltation, compared with the relatively pristine waters surrounding island reefs which are subjected to better flushing as an effect of their distance from the coast. High LHC cover was particularly observed in Auqui and General Island MPAs in which most of the stations surveyed belong to the upper $30 \%$ of the country's reefs that are considered in good health (Gomez et al. 1994). On the whole, mean live hard coral cover across all 60 stations was $50 \%$, illustrating that the area is considered to be in fair to good reef health (Gomez et al. 1994).

Except for Adlay, total algal cover (DCA + other algae) was low in the Island MPAs (Auqui and General Is.) relative to higher cover exhibited by the inshore MPAs (Fig. 4). The highest values were observed in Adlay (42\%) and in Uba (40\%) (Table 1). Both sites have extensive reef flats while the latter has, additionally, narrow reef slope portions. This factor may have contributed to algal formation in the flats extending to the reef portions.

Highest LSC cover was exhibited by Carrascal (mean $=$ $11 \%$ ) whereas lowest cover was recorded in Auqui and General Is. (both with mean $=1 \%$ ) (Table 1). Along with LSC, percent cover for DC, other biota and abiotic component altogether contributed $17 \%$ to total benthic cover in Surigao del Sur.

\section{Danajon Bank, Bohol}

Average live hard coral cover ranged from 21 to 54\% across all MPA sites in Danajon Bank, Bohol (Table 2). Sag and Bantigue MPAs exhibited relatively high LHC

Table 1 Summary of benthic cover (\%) in the 6 MPA sites in Surigao del Sur, Philippines, as a mean of ten $50 \mathrm{~m}$ line transects.

\begin{tabular}{lcccccccccccc}
\hline & \multicolumn{2}{c}{ Auqui } & \multicolumn{2}{c}{ Adlay } & \multicolumn{2}{c}{ Carrascal } & \multicolumn{2}{c}{ Capandan } & \multicolumn{2}{c}{ General Is. } & Uba \\
& Mean & SD & Mean & SD & Mean & SD & Mean & SD & Mean & SD & Mean & SD \\
\hline LHC & 63.0 & 14.2 & 49.9 & 14.9 & 44.7 & 11.9 & 46.8 & 10.4 & 58.3 & 14.1 & 37.2 & 11.3 \\
LSC & 0.9 & 1.0 & 2.7 & 2.1 & 11.4 & 11.7 & 1.1 & 1.0 & 0.9 & 2.1 & 1.6 & 1.6 \\
DC & 0.3 & 0.6 & 0.1 & 0.3 & 0.1 & 0.3 & 0.9 & 1.2 & 0.9 & 1.9 & 0.3 & 0.8 \\
DCA & 23.6 & 6.5 & 29.0 & 16.1 & 24.8 & 15.9 & 32.1 & 13.7 & 22.4 & 10.6 & 17.3 & 7.8 \\
Other Algae & 5.5 & 7.9 & 12.7 & 9.2 & 3.3 & 2.3 & 5.6 & 5.2 & 0.6 & 1.1 & 22.9 & 16.7 \\
Other Biota & 1.7 & 1.5 & 0.8 & 0.6 & 2.3 & 2.5 & 3.1 & 2.8 & 2.3 & 2.5 & 7.9 & 7.5 \\
Abiotic & 5.1 & 6.2 & 4.7 & 7.2 & 13.5 & 20.2 & 10.4 & 11.4 & 14.5 & 12.1 & 12.8 & 11.5 \\
\hline
\end{tabular}




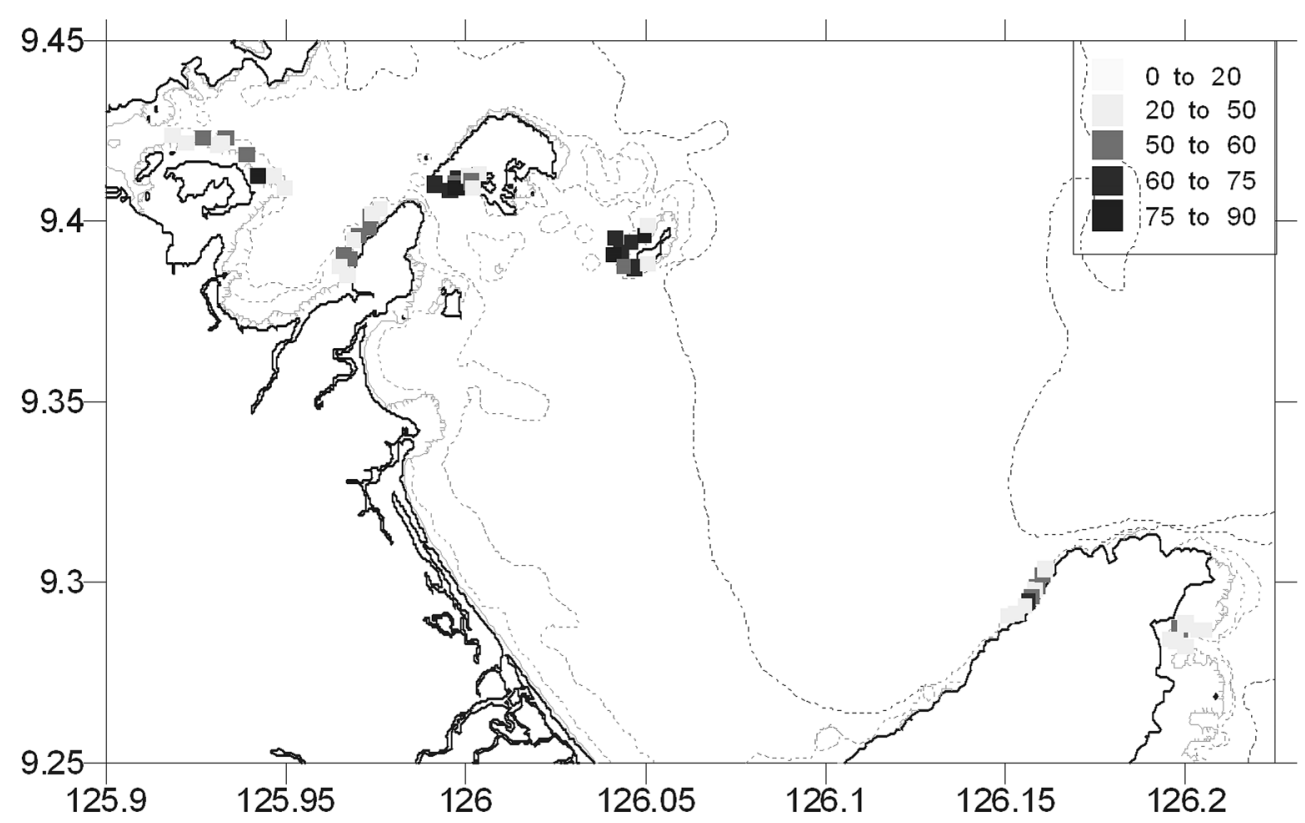

Fig. 3 The distribution of live hard coral (LHC) cover (\%) estimates in the six reef MPA sites in Surigao del Sur, Philippines in May-June, 2008

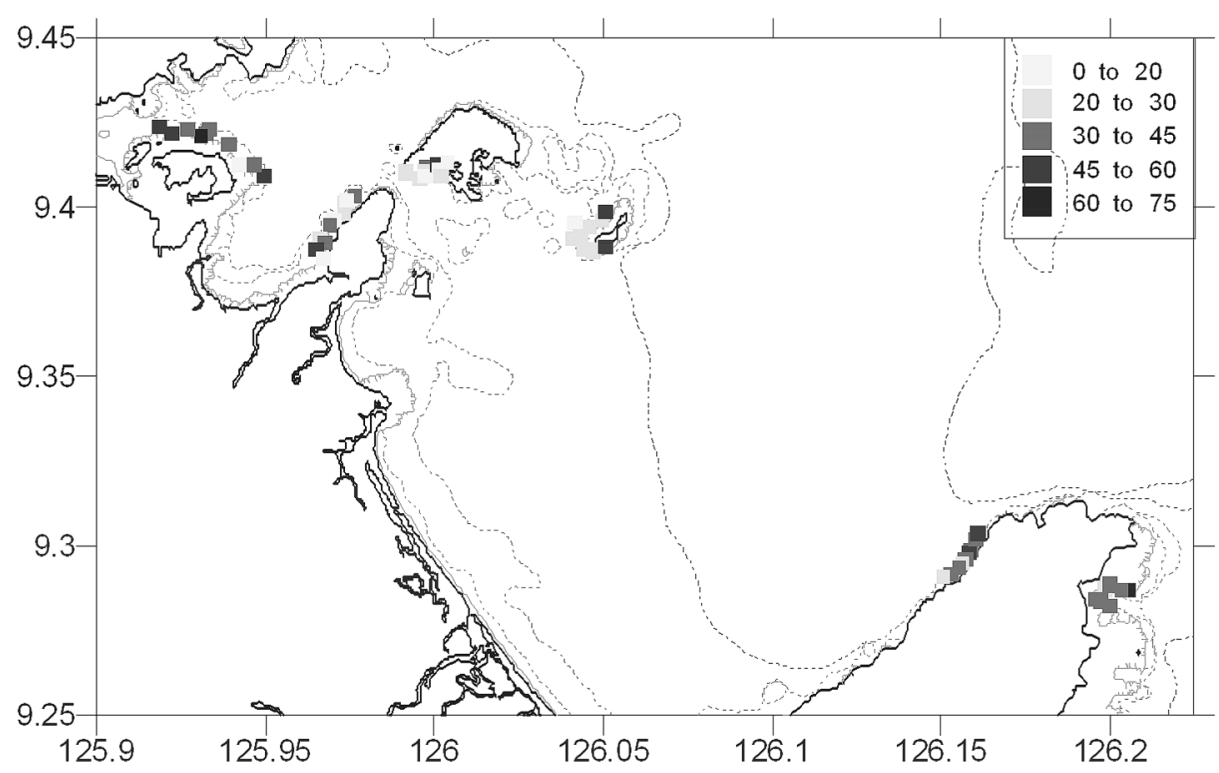

Fig. 4 The distribution of total algal cover (\%) (DCA + Other Algae) estimates in the six reef MPA sites in Surigao del Sur, Philippines in May-June, 2008.

cover (two times higher) than in the other MPA sites (Table 2 and Fig. 5). Although all sites are contained within a double barrier reef system, the significantly high LHC cover shown by Sag and Bantigue MPAs may be attributed to the rather small size of their reef areas and the island itself(Fig. 5) thus the lower population size and lesser exposure to anthropogenic activities.

Total algal cover (DCA + other algae) was lowest in Bantigue (9\%) and Sag (14\%), which have high LHC cover, and was high in the other 4 sites with low LHC cover (Figs. 5-6). As in the case of Surigao del Sur, relatively high total algal estimates in Cataban (28\%), 
Table 2 Summary of benthic cover (\%) in the 6 MPA sites in Danajon Bank, Bohol, central Philippines, as a mean of 10 to $1250 \mathrm{~m}$ line transects.

\begin{tabular}{|c|c|c|c|c|c|c|c|c|c|c|c|c|}
\hline & \multicolumn{2}{|c|}{$\begin{array}{l}\text { Bilang- } \\
\text { Bilangan }\end{array}$} & \multicolumn{2}{|c|}{ Bantigue } & \multicolumn{2}{|c|}{ Cataban } & \multicolumn{2}{|c|}{ Hingutanan } & \multicolumn{2}{|c|}{ Pinamgo } & \multicolumn{2}{|c|}{ Sag } \\
\hline & Mean & SD & Mean & SD & Mean & $\mathrm{SD}$ & Mean & SD & Mean & $\mathrm{SD}$ & Mean & SD \\
\hline LHC & 20.8 & 11.3 & 44.9 & 18.6 & 23.0 & 13.4 & 21.0 & 13.3 & 22.9 & 19.0 & 53.6 & 18.1 \\
\hline LSC & 13.6 & 8.9 & 6.1 & 4.6 & 6.0 & 7.5 & 9.2 & 6.2 & 0.1 & 0.3 & 2.0 & 5.0 \\
\hline DC & 0.9 & 2.1 & 6.5 & 9.2 & 1.8 & 3.1 & 0.2 & 0.3 & 5.6 & 7.8 & 9.9 & 10.1 \\
\hline $\begin{array}{l}\text { DCA } \\
\text { Other }\end{array}$ & 19.6 & 10.0 & 8.8 & 7.8 & 16.7 & 9.0 & 15.0 & 8.4 & 2.0 & 5.0 & 7.9 & 11.5 \\
\hline $\begin{array}{l}\text { Algae } \\
\text { Other }\end{array}$ & 0.1 & 0.2 & 0.2 & 0.4 & 10.8 & 14.3 & 2.1 & 5.1 & 22.5 & 5.9 & 5.9 & 6.5 \\
\hline Biota & 2.7 & 2.2 & 5.5 & 5.0 & 4.6 & 4.4 & 2.4 & 1.8 & 7.9 & 9.8 & 3.0 & 2.3 \\
\hline Abiotic & 42.4 & 15.8 & 28.0 & 22.3 & 37.2 & 17.9 & 50.2 & 19.7 & 39.1 & 22.6 & 17.7 & 13.3 \\
\hline
\end{tabular}

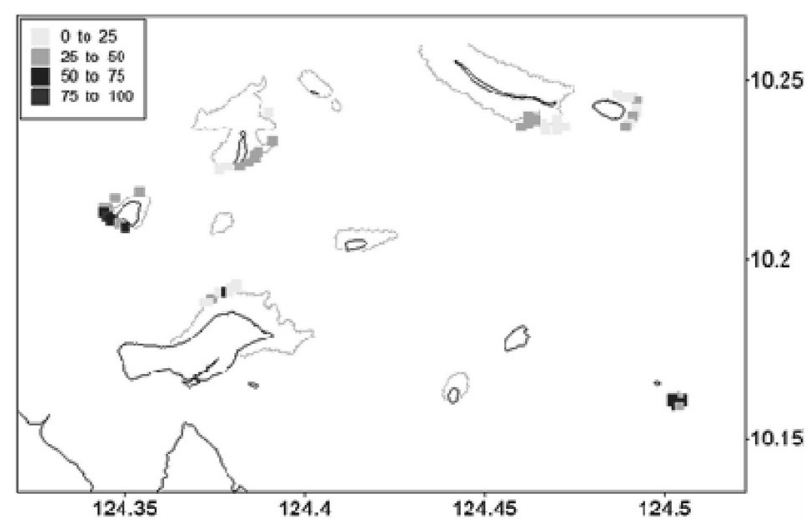

Fig. 5 The distribution of live hard coral (LHC) cover (\%) estimates in the six reef MPA sites in Danajon Bank, Bohol, in August 2008.

Pinamgo (25\%), and Bilang-Bilangan (20\%) may be due to the factor of having extensive tidal reef flats extending to the reef portions.

On the other hand, live soft coral (LSC) cover was generally low $(0-14 \%)$ in this portion of Danajon Bank, along with DC and other biota (Table 2).

In contrast to sites surveyed in Danajon Bank (Table 2) with an overall mean of $36 \%$. During the dive surveys, reefs in most stations were observed to be patchily distributed along sandy bottoms. This apparently contributed to low biotic and high abiotic cover estimates.

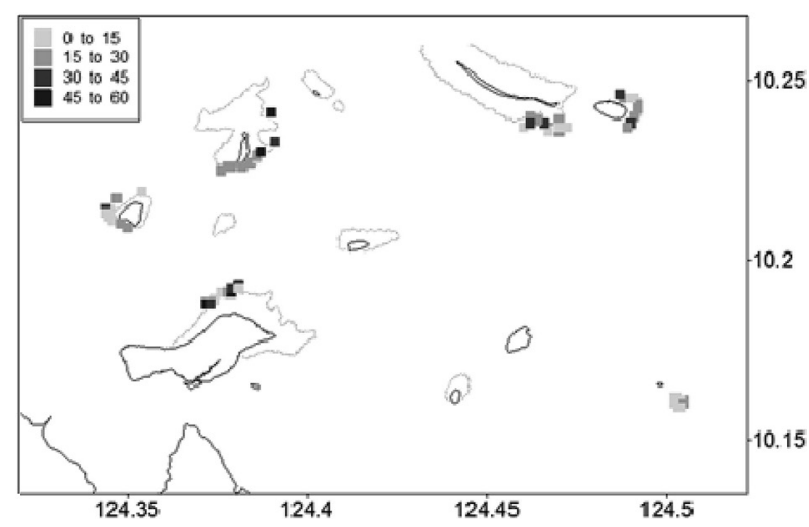

Fig. 6 The distribution of total algal cover (\%) (DCA+ Other Algae) estimates in the six reef MPA sites in Danajon Bank, Bohol, in August 2008.

\section{Data Analysis}

For Surigao del Sur, the one way ANOVA showed significant within-MPA variability in LHC (average distance between transects $=200-300 \mathrm{~m}$ ) for some sites, but also showed significant between-MPA differences in LHC cover for other sites (ANOVA, $p=0.0006$ ) (Fig. 7). Interestingly, Auqui MPA, with the highest mean LHC, was found to be significantly different only from the inshore MPAs, Capandan, Carrascal and Uba, but was not significantly different from the other two island MPAs, Adlay and General Island. A similar pattern was observed in the subtropical reefs in Eastern Australia where a significant 


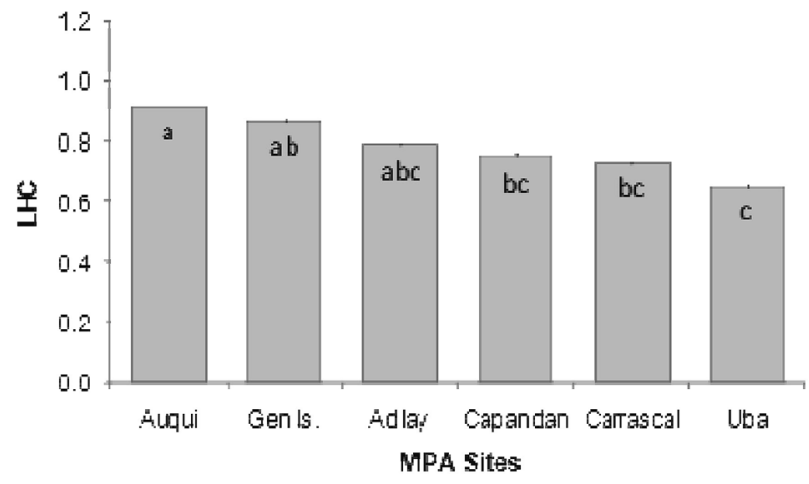

Fig. 7 Univariate analysis for LHC (\%) in Surigao del Sur, Philippines. The letters indicate significantly different means based on multiple comparisons test.

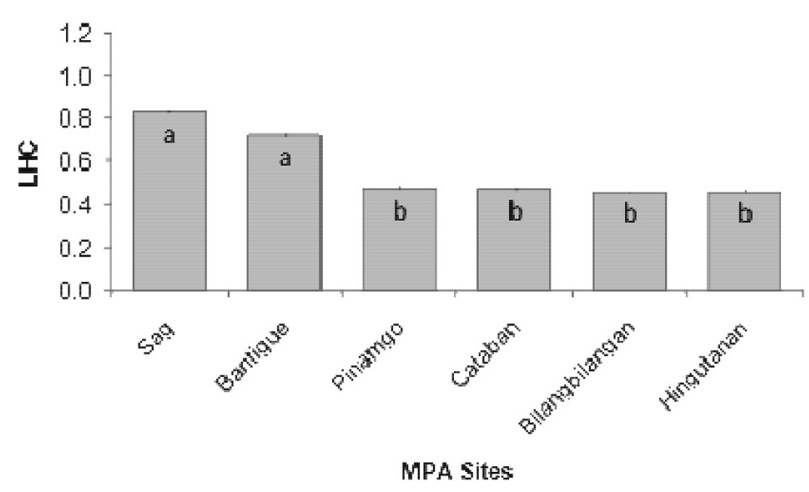

Fig. 8 Univariate analysis for LHC (\%) in Danajon Bank, Bohol, Philippines. The letters indicate significantly different means based on multiple comparisons test.

difference in coral cover was observed between inshore sites and island sites (Harriot et al. 1994). Adlay MPA, which is the only island MPA closest to the mainland and more exposed to anthropogenic disturbance, was not significantly different from any of the five other MPAs.

In Danajon Bank, however, the same analysis revealed very little variation in LHC cover among sites within the study area (Fig. 8). Furthermore, coral cover was relatively homogeneous among transects within sites. This may be so since all MPA sites surveyed in Danajon Bank are island MPAs contained within a double barrier reef system showing a lesser exposure to open water oceanographic processes compared to the relatively exposed reef systems in Surigao del Sur. In addition, the significant difference in the variation of LHC exhibited by Sag and Bantigue MPAs from all the other four MPAs in Danajon Bank

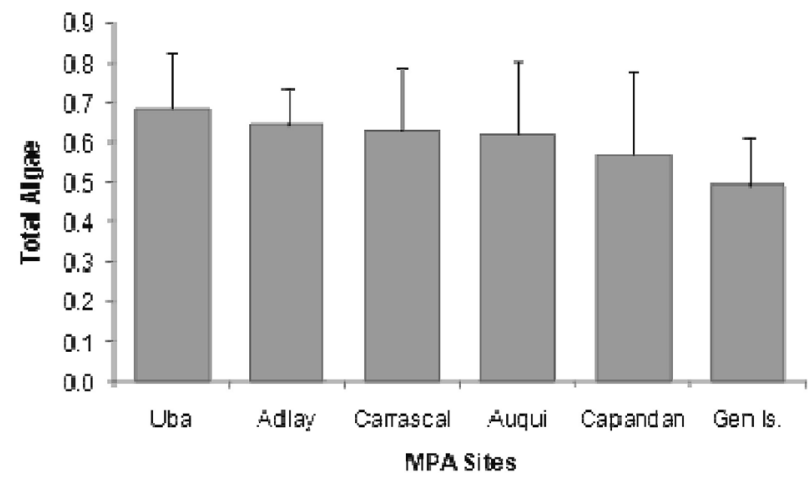

Fig. 9 Univariate analysis for total algal cover (\%, DCA + total algae) in Surigao del Sur, Philippines

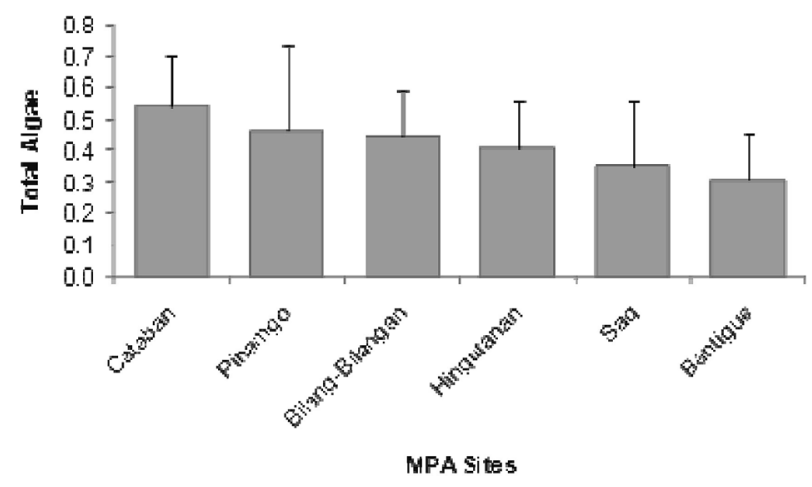

Fig. 10 Univariate analysis for total algal cover (\%, DCA + total algae) in Danajon Bank, Bohol, Philippines.

(ANOVA, $p=0.000007$ ) may be due to the higher fishing pressure in the latter MPAs and the relatively smaller land and reef area in the former as well as the smaller population size.

Univariate analysis was also applied to test levels of variability on total algal cover (DCA + Other algae) in the different MPA sites. No significant difference was observed between MPA sites in both Surigao del Sur (Fig. 9) and Danajon Bank, Bohol (Fig. 10) and variability in total algal cover was rather low.

To get an idea on the effect of distance on live hard coral cover, the variogram analysis was employed. Results showed spatial autocorrelation up to $2 \mathrm{~km}$ in Surigao del Sur (Fig. 11) and up to $0.8 \mathrm{~km}$ in Danajon Bank, Bohol (Fig. 12). Somehow, a linear relation of variability with distance is exhibited in both areas but the experimental variograms seem to be rather wavy or inconsistent (Figs. 11-12). This pattern may indicate that at certain distances 


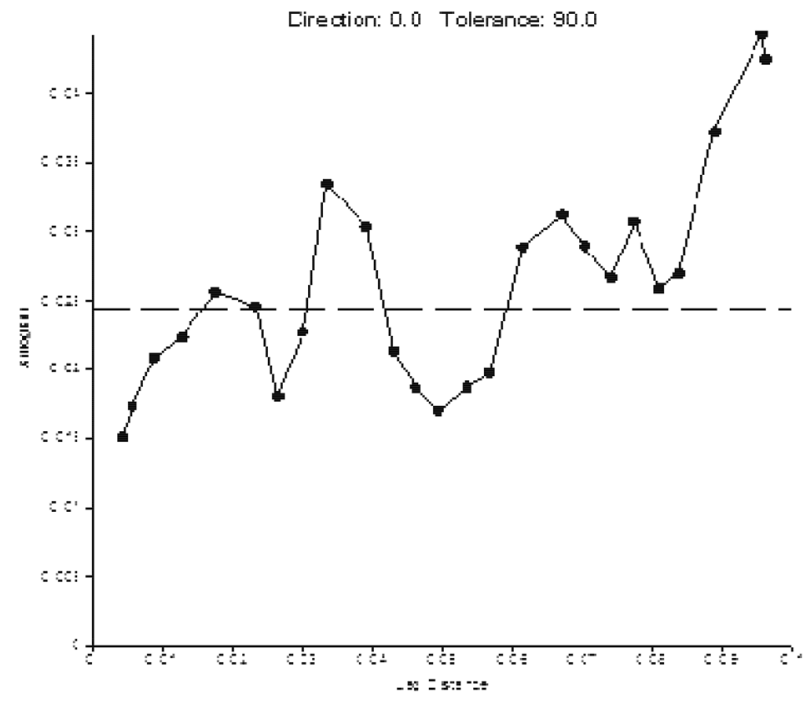

Fig. 11 Variogram for live hard coral cover (\%) in Surigao del Sur, Philippines. Variability is reached between 1 and $2 \mathrm{~km}$ but the discontinuity in the distribution may be an effect of abiotic factors rather than distance. Note: lag distance of $0.01=1 \mathrm{~km}$.

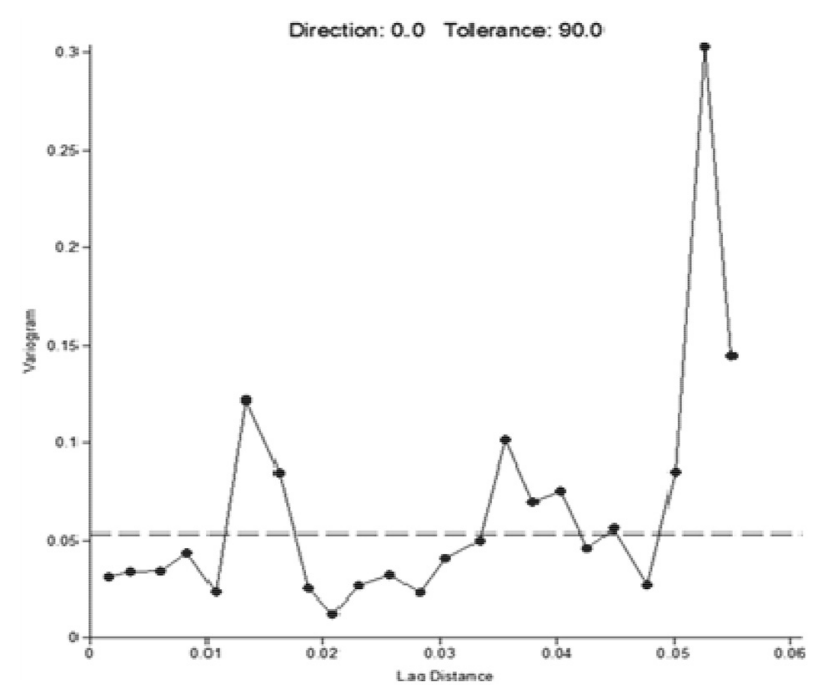

Fig. 12 Variogram for live hard coral cover (\%) in Danajon Bank, Bohol, Philippines. Note: lag distance of $0.01=1 \mathrm{~km}$.

between points there is less difference between the sites than at other distances. Discontinuities in the distribution displayed after $2 \mathrm{~km}$ and $0.8 \mathrm{~km}$ in Surigao del Sur and Danajon Bank, respectively, may be attributed to abiotic and other environmental factors or could be the existence of repetitive structures of reefs rather than an effect of distance between transect sites.
Variability is high in both survey areas, but at least in terms of LHC, there is significantly high variability within MPA sites, particularly in inshore areas where they may be more exposed to additional stresses like those caused by wave actions and possible siltation. MPAs in the islands are largely located on the leeward side of islands. Variability is not so much a function of distance than it is a function of local physical habitat structure, such as islands vs. main land coast, leeward vs. exposed, and proximity to circulation in open waters.

Measuring variability of coral assemblages across different scales i.e. finer scale (within several meters in a $50 \mathrm{~m}$ line transect) is recommended. An understanding of how coral assemblages vary through space will help in devising sampling strategies essential in tracking the dynamics of coral reefs (Murdoch and Aronson, 1999) and in a way help in effectively managing reef MPAs in the country.

\section{Acknowledgements}

This study is part of a 7-year program of the Fisheries Improved for Sustainable Harvest (FISH) Project funded by USAID. We thank local residents and the staff of field offices of the FISH project in Surigao del Sur and Danajon Bank, Bohol for their assistance, and the staff of the OceanBio and Marine Bio Labs of the College of Arts and Sciences of the University of the Philippines Visayas for providing their technical expertise during the survey. Travel grant was provided by the organizers of the 2 nd APCRS to attend the symposium.

\section{References}

Armstrong M, Renard D, Rivoirard J, Petitgas P (1992) Geostatistics for fish survey data. Course publicised by ICES, Centre de Geostatistique. ENSMP, Fontainebleau. 89 p.

Barnes R (1991) The Variogram Sill and the Sample Variance, Math Geol 23 (4): 673-678

Bradbury RH, Young PC (1983) Coral interactions and community structure: an analysis of spatial pattern. Mar Ecol Prog Ser 11: 265-271 
Campos WL (2008) Monitoring and assessment of marine protected areas in FISH Project focal areas: Surigao del Sur.

Coral Reef Information Network of the Philippines (Philreefs). 2003. Philippine Coral Reefs through Time (2003): Workshop Proceedings. Second of the Atlas of Philippine Coral Reefs Series. Coral Reef Information Network of the Philippines (PhilReefs), University of the Philippines Marine Science Institute, Quezon City, Philippines and the Marine Parks Center, Tokyo, Japan.

English S, Wilkinson C, V Baker (eds). 1994. Survey manual for tropical marine resources. Australian Institute of Marine Science, Australia, p 368

Gomez ED, Alino PM, Yap HT, Licuanan WY (1994) A review of the status of Philippine reefs. Mar Poll Bull 29 (1-3): 62-68
Harriot VJ, Smith SDA, Harrison PL (1994) Patterns of coral community structure of subtropical reefs in the solitary islands marine reserve, eastern Australia. Mar Ecol Prog Ser 109: 67-76

Mous PJ, Muljadi A, Purwanto, Pet JS (2005) Status of coral reefs in and around Komodo National Park. Results of a bi-annual survey over the period 1996-2002 (July 2005). Publication from The Nature Conservancy Southeast Asia Center for Marine Protected Areas, Sanur, Bali, Indonesia. p 57

Murdoch TJT, Aronson RB (1999) Scale-dependent spatial variability of coral assemblages along the Florida Reef Tract. Coral Reefs 18: 341-351

Zar JH (1996) Biostatistical analysis, Prentice-Hall: USA

(C) Japanese Coral Reef Society 